\title{
Polaron and Spin Dynamics in Organic-Inorganic Lead Halide Perovskite Nanocrystals
}

\section{Journal Article}

Author(s):

Shrivastava, Megha; Bodnarchuk, Maryna I.; Hazarika, Abhijit; Luther, Joseph M.; Beard, Matthew C.; Kovalenko, Maksym V.; Adarsh, K.V.

\section{Publication date:}

2020-12-17

\section{Permanent link:}

https://doi.org/10.3929/ethz-b-000449979

\section{Rights / license:}

In Copyright - Non-Commercial Use Permitted

\section{Originally published in:}

Advanced Optical Materials 8(24), https://doi.org/10.1002/adom.202001016 


\section{WILEY-VCH}

\section{Polaron and Spin Dynamics in Organic-Inorganic}

\section{Lead Halide Perovskite Nanocrystals}

Megha Shrivastaval, Maryna I. Bodnarchuk ${ }^{2}$, Abhijit Hazarika ${ }^{3}$,Joseph M. Luther ${ }^{4}$, Matthew C Beard ${ }^{4}$, Maksym V. Kovalenko ${ }^{2,5}$, and K. V. Adarsh ${ }^{1 *}$

${ }^{1}$ Department of Physics, Indian Institute of Science Education and Research, Bhopal 462066 India

${ }^{2}$ Empa - Swiss Federal Laboratories for Materials Science and Technology, CH-8600 Dübendorf, Switzerland

${ }^{3}$ Polymer and Functional Materials Division, Indian Institute of Chemical Technology, Hyderabad 500007, India

${ }^{4}$ Chemistry and Nanoscience Science Center, National Renewable Energy Laboratory, Golden, Colorado 80401, USA

${ }^{5}$ Laboratory of Inorganic Chemistry, Department of Chemistry and Applied Biosciences, ETH Zürich, CH-8093 Zürich, Switzerland

\section{Corresponding Author*}

Email: adarsh@,iiserb.ac.in

\section{ORCID}

Abhijit Hazarika: 0000-0003-0391-2163

Joseph M. Luther: 0000-0002-4054-8244

Matthew C Beard: 0000-0002-2711-1355

Maksym V. Kovalenko: 0000-0002-6396-8938

K.V. Adarsh: 0000-0002-6337-6545

\section{Keywords:}

Polarons, organic-inorganic lead halide perovskite, spin dynamics 


\section{WILEY-VCH}

Abstract:

Long-lived carrier population and spin-based behavior in lead halide perovskite nanocrystals (NCs) are extremely interesting for implementing photovoltaic devices with efficiencies exceeding the Shockley-Queisser limit and quantum information processing, respectively. However, a comprehensive understanding of polaron mediated charge-carrier interactions and an accurate description of the spin-polarized states for spintronics are still lacking. In this article, we studied the carrier and spin interactions under controlled conditions in $\mathrm{FAPbI}_{3}$ and $\mathrm{Cs}_{0.01} \mathrm{FA}_{0.99} \mathrm{~Pb}\left(\mathrm{Br}_{\left.0.11 I_{0.89}\right)_{3}} \mathrm{NCs}\right.$ through ultrafast transient absorption (TA) spectroscopy. At early time scales, TA spectrum shows an asymmetric derivative feature originating from the hot carrier induced spectral redshift in $\mathrm{FAPbI}_{3} \mathrm{NCs}(55 \pm 3 \mathrm{meV})$ and $\mathrm{Cs}_{0.01} \mathrm{FA}_{0.99} \mathrm{~Pb}\left(\mathrm{Br}_{0.11} \mathrm{I}_{0.89}\right)_{3}$ NCs $(54 \pm 2 \mathrm{meV})$ at the bandedges that stabilizes to $9 \pm 1 \mathrm{meV}$ and $11 \pm 2 \mathrm{meV}$, respectively, at 1 ps due to the polaron formation. The kinetic analysis indicates that the polaron populations in $\mathrm{FAPbI}_{3}$ and $\mathrm{Cs}_{0.01} \mathrm{FA}_{0.99} \mathrm{~Pb}\left(\mathrm{Br}_{0.11} \mathrm{I}_{0.89}\right)_{3} \mathrm{NCs}$ decay with an average lifetime of $657 \pm 34$ and $532 \pm 28$ ps, respectively. The circular polarization-resolved TA reveals that polaron formation can control spin-relaxation in NCs, thus providing a powerful tool to explore the development of their prospective applications in spintronics.

\section{Introduction}

Organic-inorganic lead halide perovskites nanocrystals (OILHP NCs) of the general formula $\mathrm{APbX}_{3}\left(\mathrm{~A}=\right.$ methylammonium $\left(\mathrm{MA}^{+}\right) /$formamidinium $\left(\mathrm{FA}^{+}\right) / \mathrm{Cs}^{+} / \mathrm{Rb}^{+}$and $\left.\mathrm{X}=\mathrm{I} / \mathrm{Br} / \mathrm{Cl}\right)$ are extremely interesting for a wide range of applications in electronics, optoelectronics and quantum information processing ${ }^{[1-6]}$. OILHP NCs show low trap density $\left(10^{10} / \mathrm{cm}^{3}\right)$ and exceptional defect tolerance even when prepared at room temperature, where a high defect density is unavoidable ${ }^{[7-11]}$. Seminal demonstrations of defect tolerance include charge-carrier lifetimes $\sim 2 \mu \mathrm{s}$, long carrier diffusion lengths $\sim 10 \mu \mathrm{m}$, and high photoluminescence quantum yield $^{[7,11-15]}$. These attributes led to extremely efficient solution-processed cost-effective solar cells $(22 \%)$, low-threshold lasing, and light-emitting diodes ${ }^{[2,5,12,16-21]}$. Recently demonstrated 


\section{WILEY-VCH}

hot-phonon bottleneck helps to establish the potential for hot carrier photovoltaic devices that can break the single-junction Schokley-Queisser limit for solar cells ${ }^{[22,23]}$.

Among OILHP NCs, the rapid emergence of $\mathrm{FAPbI}_{3}$ and quinary $\mathrm{Cs}_{0.01} \mathrm{FA}_{0.99} \mathrm{~Pb}\left(\mathrm{Br}_{0.11} \mathrm{I}_{0.89}\right)_{3}$ NCs are attributed to the appreciably high phase/chemical stabilities, possibility to fine-tune the absorption and emission spectrum with high quantum yield $\sim 89 \%$, and the appropriate bandgap for solar cell applications ${ }^{[12]}$. The electronic band structure of OILHP consists of $\mathrm{Pb}(s$ orbitals $)$ and $\mathrm{X}$ ( $p$ orbitals $)$ in the valence band, and $\mathrm{Pb}(p$ orbitals $)$ and $\mathrm{X}$ (s orbitals) in the conduction band $^{[1,8]}$. Strikingly, the Young and bulk moduli of OILHP lie between $\approx 10$ and $25 \mathrm{GPa}$, making their lattice soft and thus easily undergoing structural changes compared to other inorganic semiconductors with similar electronic properties ${ }^{[1]}$. Although A site cations do not directly participate in the electronic structure, still their rotations locally affect the $\mathrm{Pb}-\mathrm{X}$ sub-lattice and localize charge carriers across many unitcells ${ }^{[9,10,24,25]}$. All these exceptional performances indicate that charge-carriers may be protected from defect scattering because of the unusually strong coupling between the structural and electronic dynamics, in which the dynamically screened Coulomb potential minimizes charge-carrier scattering by the formation of polarons ${ }^{[9,10,25-27]}$. Such behavior of carrier protection by polarons (carriers dressed by the longrange polarized lattice deformation) has already been demonstrated in OILHP single crystals $^{[9,10,25-28]}$. The formation of polarons in OILHP is the direct outcome of the intrinsic softness and the polarizability of $\mathrm{Pb}-\mathrm{X}$ lattice ${ }^{[10,26,29,30]}$. Even though photophysics and carrier dynamics in OILHP single crystals have been intensively studied, such investigations on confined NCs are rather limited. Moreover, most previous studies on the carrier dynamics in NCs have not considered the role of polarons. Here, we demonstrate the polaron mediated carrier dynamics of $\mathrm{FAPbI}_{3}$ and $\mathrm{Cs}_{0.01} \mathrm{FA}_{0.99} \mathrm{~Pb}\left(\mathrm{Br}_{0.11} \mathrm{I}_{0.89}\right)_{3} \mathrm{NCs}$ using ultrafast transient absorption (TA) spectroscopy. Our studies reveal hot-carrier induced redshift of the bandedge $55 \pm 3 \mathrm{meV}(54 \pm 2 \mathrm{meV})$ for $\mathrm{FAPbI}_{3}\left(\mathrm{Cs}_{0.01} \mathrm{FA}_{0.99} \mathrm{~Pb}\left(\mathrm{Br}_{0.11} \mathrm{I}_{0.89}\right)_{3}\right) \mathrm{NCs}$ at early times that then stabilize to polarons in $\sim 1$ ps. In $\mathrm{FAPbI}_{3} \mathrm{NCs}$, the bandedge polarons are stable for $\sim 30 \mathrm{ps,}$ 


\section{WILEY-VCH}

and after that they decay with an average lifetime of $657 \pm 34$ ps. However, the polarons in $\mathrm{Cs}_{0.01} \mathrm{FA}_{0.99} \mathrm{~Pb}\left(\mathrm{Br}_{0.11} \mathrm{I}_{0.89}\right)_{3} \mathrm{NCs}$ are stabilized for only $\sim 5 \mathrm{ps}$ and then decay with an average lifetime $532 \pm 28$ ps. We attribute the fast decay in $\mathrm{Cs}_{0.01} \mathrm{FA}_{0.99} \mathrm{~Pb}\left(\mathrm{Br}_{0.11} \mathrm{I}_{0.89}\right)_{3}$ NCs to the reduced lattice softness and polarizability arising from $\mathrm{Cs}^{+}$and $\mathrm{Br}^{-}$exchange. In addition to carrier protection, polarons were found to affect the spin-relaxation time of spin-polarized charge-carriers.

\section{Results and Discussion}

\subsection{Ground State Optical Absorption}

Optical absorption spectra of $\mathrm{FAPbI}_{3}$ and $\mathrm{Cs}_{0.01} \mathrm{FA}_{0.99} \mathrm{~Pb}\left(\mathrm{Br}_{0.11} \mathrm{I}_{0.89}\right)_{3}$ NCs (see method section for synthesis), presented in Figure 1a and 1b demonstrate a sharp onset of absorption, which is traditionally modeled with Elliott's equation that separates the exciton and free-carrier contributions from the mixed spectrum ${ }^{[17,31]}$. Since this model does not take into account the role of the strong carrier-phonon coupling in OILHPs, we employ a modified version of the Elliott equation as shown below ${ }^{[17,32-36]}$

$$
\begin{aligned}
\alpha(E)=\alpha_{p h}(E)+\alpha_{c}(E)= & B_{p h} \sum_{n=1}^{\infty}\left[\sum_{j=0}^{3} \frac{4 \pi}{n^{3}}\left(\frac{e^{-S} S^{j}}{j !}\right) \operatorname{Sech}\left(\frac{E-\left(E_{g}-\frac{E_{b}}{n^{2}}\right)+j E_{L O}}{\Gamma_{p h}}\right)\right] \\
& +B_{c}\left[\int_{E_{g}}^{\infty} \operatorname{Sech}\left(\frac{E-\varepsilon}{\Gamma_{c}}\right) \frac{2 \pi}{1-e^{-\frac{2 \pi}{\sqrt{\varepsilon}}}} d \varepsilon\right]
\end{aligned}
$$

Where $B_{p h}$ and $B_{c}$ are constants, while $S, E, E_{L O}, E_{g}$, and $E_{b}$ are Huang-Rhys factor, photon energy, longitudinal optical (LO) phonon energy, bandgap, and binding energy of exciton, respectively. $\Gamma_{p h}$ and $\Gamma_{c}$ are broadening parameters for the phonon dressed exciton and freecarriers, respectively. The polaron and continuum contributions of the band edge absorption spectrum are separated by fitting the experimental data using the modified Elliott equation (details in Supporting Information), and the fitting parameters are tabulated in Table 1. The absorption contributions of the excitons (black curve), phonon replicas (pink, orange, and 


\section{WILEY-VCH}

purple curve), and continuum (green curve) from the spectral fitting are shown in Figure 1a and 1b. Optical bandgap calculated using Equation 1 for $\mathrm{FAPbI}_{3}$ and $\mathrm{Cs}_{0.01} \mathrm{FA}_{0.99} \mathrm{~Pb}\left(\mathrm{Br}_{0.11} \mathrm{I}_{0.89}\right)_{3} \mathrm{NCs}$ are $\sim 1.72$ and $1.74 \mathrm{eV}$, respectively, in agreement with the previous reports ${ }^{[12,37]}$. Exciton and three phonon replica (by redistributing the intensity of the primary excitonic transition using Poisson distribution) contribute a polaron band centered at $\sim 1.69 \mathrm{eV}$ for $\mathrm{FAPbI}_{3} \mathrm{NCs}$ and at $\sim 1.72 \mathrm{eV}$ for $\mathrm{Cs}_{0.01} \mathrm{FA}_{0.99} \mathrm{~Pb}\left(\mathrm{Br}_{0.11} \mathrm{I}_{0.89}\right)_{3} \mathrm{NCs}$ (blue curve in Figure 1a and 1b). Consequently, the polaron binding energy $\left(E_{p}\right)$ calculated by taking the difference between continuum and polaron band is $30 \mathrm{meV}(20 \mathrm{meV})$ for $\mathrm{FAPbI}_{3}$ $\left(\mathrm{Cs}_{0.01} \mathrm{FA}_{0.99} \mathrm{~Pb}\left(\mathrm{Br}_{0.11} \mathrm{I}_{0.89}\right)_{3}\right)$ NCs. We observe a strong and narrow (FWHM $\sim 100 \mathrm{meV}$ )

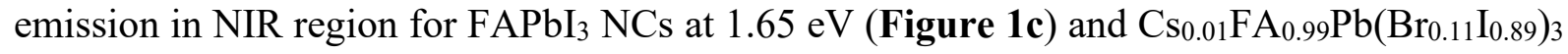
NCs at $1.69 \mathrm{eV}$ (Figure 1d). The transmission electron microscopy (TEM) images in Figure $\mathrm{S} 1 \mathrm{a}$ and $\mathrm{S} 1 \mathrm{~b}$ in the Supporting Information show that $\mathrm{FAPbI}_{3} \mathrm{NCs}$ and $\mathrm{Cs}_{0.01} \mathrm{FA}_{0.99} \mathrm{~Pb}\left(\mathrm{Br}_{0.11} \mathrm{I}_{0.89}\right)_{3} \mathrm{NCs}$ have the same cubic morphology with an average edge length of $11 \mathrm{~nm}$.

\subsection{Carrier Protection and Polaron Formation in $\mathrm{FAPbI}_{3} \mathrm{NCs}$}

To decipher the polaron dynamics in the soft lattice of OILHP NCs, we first measured the ultrafast TA spectrum of the $\mathrm{FAPbI}_{3} \mathrm{NCs}$ with above bandgap pump pulses $(400 \mathrm{~nm})$ of moderate fluence $3 \mu \mathrm{J} / \mathrm{cm}^{2}$ (details in experimental method section). Pump pulses generate hotcarriers instantaneously described by an elevated carrier temperature $\left(T_{c}\right)$ that first equilibrate and form a thermal distribution through carrier-carrier scattering, followed by the transfer of their excess energy to the lattice through carrier-phonon interactions and finally relax to the band-edge ${ }^{[17,35,38-40]}$. Figure 2a shows the contour representation of the TA spectrum of $\mathrm{FAPbI}_{3}$ NCs, and Figure 2b presents the respective cross-sections. For a structured discussion, we have divided the TA spectrum into two timescales (1) early times $\Delta t \leq 1 \mathrm{ps}$ and (2) late times $\Delta t>1 \mathrm{ps}$. In the early timescales, the spectral data appear as an asymmetric derivative feature with photoinduced redshifted absorption below the polaronic level and bleach near the band- 


\section{WILEY-VCH}

edge (details in Supporting Information and Figure S2) ${ }^{[41,42]}$. A similar derivative feature is not observed for near band-edge excitation of $700 \mathrm{~nm}$ (Figure S3, Supporting Information), which confirms that this predominantly arises due to the presence of hot-carriers ${ }^{[43,44]}$. Concurrent to the JDOS shift, pump excitation also redshifts the polaron absorption (details in Supporting Information and Figure S2). As time progresses, $\Delta \mathrm{t} \geq 1 \mathrm{ps}$, a strong bleach replaces the derivative lineshape $\mathrm{e}^{[17,43]}$. Then a weak and broad photoinduced absorption (PIA) develops towards high energy side $(\sim 1.8 \mathrm{eV})$. The PIA originates due to the activation of forbidden transitions above bandgap due to the lattice deformation associated with the polarons in the system $^{[45]}$. To quantify the spectral shift induced by the hot-carriers, we have carried out the global analysis of TA spectrum by assuming that the bandedge absorption is described by

$$
\Delta A(E, t)=\Delta A_{p h}(E, t)+\Delta A_{c}(E, t)
$$

where $\Delta \mathrm{A}_{\mathrm{ph}}(\mathrm{E}, \mathrm{t})$ and $\Delta \mathrm{A}_{\mathrm{c}}(\mathrm{E}, \mathrm{t})$ individually represent the change in polaron and continuum contributions. The expanded form of Equation 2 is given in Supporting Information and the solid lines in Figure $\mathbf{2 b}$ show the representative fits . The corresponding fitting parameters are listed in Table 2. The redshift obtained using Equation 2 is as much as $55 \pm 3 \mathrm{meV}$ at $0.6 \mathrm{ps,}$ decreasing and eventually stabilizing $9 \pm 1 \mathrm{meV}$ at $1 \mathrm{ps}$. Since the Coulombic interactions are screened by polarons, the time over which the redshifted absorption decays will give the polaron formation time ${ }^{[9,10,25-27]}$.

To elucidate the polaron formation, we have assessed the charge-carrier relaxation processes from the kinetic traces of $\mathrm{FAPbI}_{3} \mathrm{NCs}$ (Figure 2c). From the figure, it can be noticed that the two kinetic curves i.e., redshifted absorption at $1.62 \mathrm{eV}$ and polaronic bleach at $1.68 \mathrm{eV}$, merge and reach a quasi-steady state in $0.75 \pm 0.03$ ps (polaron formation time/bleach buildup/absorption decay time) and then remain stable until 30 ps. At initial time the dynamics are dominated by spectral-redshift, evidenced from red-dashed line in Figure 2a. Further, from Figure 2c it is clear that at initial times the magnitude of bleach due to spectral shift is less than $17 \%$ of the total bleach since carriers are not thermalized. For gaining more meaningful insights, 


\section{WILEY-VCH}

we have extracted hot-carrier temperature $\left(T_{c}\right)$ by fitting the high energy tail of the TA spectrum using Maxwell-Boltzmann distribution ${ }^{[17,35,39,44,46]}$

$$
\Delta \mathrm{A}=\mathrm{A}_{1} \mathrm{e}^{-\left(\frac{\mathrm{E}}{\mathrm{K}_{\mathrm{B}} \mathrm{T}_{\mathrm{c}}}\right)}
$$

where $K_{B}$ and $E$ are Boltzmann constant and probe photon energy $=\hbar \omega$, respectively. Figure S4 in Supporting Information presents the extracted $\mathrm{T}_{\mathrm{c}}$ as a function of probe delay and corresponding high energy TA tail fitting. The room temperature thermalization time of $0.35 \pm 0.02 \mathrm{ps}$ obtained at this low carrier density regime (on the order of $10^{14} \mathrm{~cm}^{-3}$ corresponding fluence of $3 \mu \mathrm{J} / \mathrm{cm}^{2}$ ) is longer than the reported values of conventional semiconductors like $\mathrm{GaAs}^{[47]}$. At this point, many questions are open. For instance, the long thermalization time compared to conventional semiconductors in our experiment cannot be attributed to the hot phonon bottleneck since the density of charge-carriers never exceeds the value of $10^{18} \mathrm{~cm}^{-3}$ ${ }^{[26,46]}$. Likewise, the carrier thermalization time is remarkably faster than the bleach buildup/absorption decay time of $0.75 \pm 0.03 \mathrm{ps}$. This observation is in stark contrast to the usual behavior of the nearly same kinetics for bleach build-up/absorption decay and carrier thermalization ${ }^{[15,17,48]}$. We regard this unusual behavior to the physics of polaron formation. The strength of the polarons in OILHPs is determined by the S-factor given by ${ }^{[49-51]}$

$$
S \propto \frac{1}{E_{L O}}\left(\frac{1}{\varepsilon_{\infty}}-\frac{1}{\varepsilon_{S}}\right)
$$

Where $E_{L O}, \varepsilon_{\infty}$, and $\varepsilon_{s}$, are LO phonon energy, optical dielectric constant, and static dielectric constant of the material, respectively. As manifested from Equation 4, the substantial difference between $\varepsilon_{\infty}=6.9^{[52]}$ and $\varepsilon_{\mathrm{s}}=49.4^{[53]}$ result in strong carrier-phonon interactions in $\mathrm{FAPbI}_{3}$ leading to polaron formation, which reduces the Coulomb interaction related scattering phenomena $^{[9,10,25-28]}$. This effect results in the protection of bandedge carriers for $\sim 30 \mathrm{ps}$. The hallmark of such long-lived bandedge carriers in Figure 2c without decay for nearly $30 \mathrm{ps}$ and reduced spectral redshift revealed in Figure $\mathbf{2 b}$ can thus be attributed to the polaron induced screening of the many-body Coulomb potential. After $30 \mathrm{ps,} \mathrm{the} \mathrm{polarons} \mathrm{further} \mathrm{slowly}$ 


\section{WILEY-VCH}

equilibrate with the lattice, depicted by long-time decay (shaded region in Figure 2c). The biexponential fit reveals two time constants of $92 \pm 18$ ps (population amplitude $16 \pm 3 \%$ ) and $764 \pm 37$ ps (population amplitude $84 \pm 3 \%$ ) with an average lifetime of $657 \pm 34$ ps. The fast and slow decay constants here are respectively associated with free-carrier and polarons. Overall, the unique kinetics shown in Figure 2c unveils the efficient polaron protected bandedge carriers.

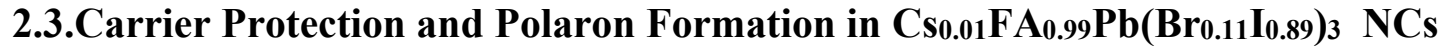

After demonstrating the polaron formation in $\mathrm{FAPbI}_{3} \mathrm{NCs}$, we have analyzed the carrier dynamics of mixed cation and mixed anion $\mathrm{Cs}_{0.01} \mathrm{FA}_{0.99} \mathrm{~Pb}\left(\mathrm{Br}_{0.11} \mathrm{I}_{0.89}\right)_{3} \mathrm{NCs}$. Figure 3a and $\mathbf{3 b}$ show the contour plot and corresponding cross-section of $\mathrm{Cs}_{0.01} \mathrm{FA}_{0.99} \mathrm{~Pb}\left(\mathrm{Br}_{0.11} \mathrm{I}_{0.89}\right)_{3} \mathrm{NCs}$. The spectral analysis using Equation 1 gives a redshift of $54 \pm 2 \mathrm{meV}$ at $0.6 \mathrm{ps}$, decreasing and eventually stabilizing $11 \pm 2 \mathrm{meV}$ within $1 \mathrm{ps}$ (the respective fitting parameters obtained at different probe delay are listed in Table 3). Also, it is evident from figures that PIA towards high energy side, attributed to polaron induced transitions, is relatively weak in comparison to $\mathrm{FAPbI}_{3} \mathrm{NCs}$, suggesting inferior polaron stability. From Figure 3c, it can be noticed that the two kinetic curves i.e., redshifted absorption at $1.66 \mathrm{eV}$ and polaronic bleach at $1.72 \mathrm{eV}$, merge and reach a quasi-steady state in $0.63 \pm 0.03 \mathrm{ps}$ (polaron formation time) and then remain stable until 5 ps. Importantly, here the polaron formation time is faster than in $\mathrm{FAPbI}_{3} \mathrm{NCs}$. This is due to the relatively small difference in excitation and bandedge energy compared to $\mathrm{FAPbI}_{3}$ NCs. The thermalization time of $\sim 0.45 \pm 0.02 \mathrm{ps}$ is obtained by the single exponential fit of $\mathrm{T}_{\mathrm{c}}$ decay (Figure S5, Supporting Information). After 5 ps, as shown in Figure 3c, the polarons equilibrate with lattice and the bi-exponential fit reveals two time constants of $89 \pm 6$ ps (population amplitude $31 \pm 2 \%$ ) and $741 \pm 39$ ps (population amplitude $69 \pm 2 \%$ ) with an average lifetime of $532 \pm 28$ ps. The two time constants obtained here are similar to that in $\mathrm{FAPbI}_{3} \mathrm{NCs}$, however, their population amplitudes are significantly different. The slightly faster carrier decay (average lifetime) and lower population amplitude of polaronic carriers in 


\section{WILEY-VCH}

$\mathrm{Cs}_{0.01} \mathrm{FA}_{0.99} \mathrm{~Pb}\left(\mathrm{Br}_{0.11} \mathrm{I}_{0.89}\right)_{3} \mathrm{NCs}$ gives an impression that $\mathrm{Cs}^{+}$and $\mathrm{Br}^{-}$substitution at the cation and anion sites leads to slightly unstable polarons. This is consistent with weak PIA towards the high energy side in TA, and lower S-factor obtained from optical absorption. The decrease in static dielectric constant due to reduced softness and polarizability on $\mathrm{Cs}^{+}$and $\mathrm{Br}^{-}$exchange

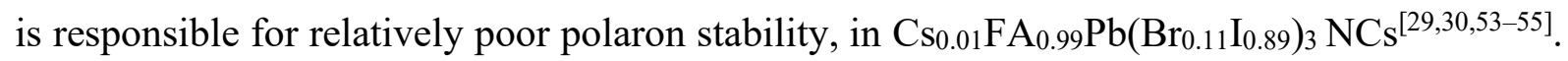
Our results indicate that composition fine-tuning is the key to tailor the polaron dynamics in perovskite NCs.

\subsection{Spin Dynamics in FAPbI 3 and Cs0.01FA0.99Pb(Bro.11 $\left.\mathrm{I}_{0.89}\right)_{3} \mathrm{NCs}$}

Polaron formation and carrier protection in OILHP is of immense interest in many potential applications, including solar cells ${ }^{[10,27]}$. The spin degrees of freedom of charge-carriers in these novel photonic quantum materials with strong spin-orbit coupling (SOC) and the polaron associated symmetry breaking offer new quantum pathways for manipulating spin via light alone without any external electric or magnetic field ${ }^{[56-60]}$. We studied the spin interactions in $\mathrm{FAPbI}_{3}$ and $\mathrm{Cs}_{0.01} \mathrm{FA}_{0.99} \mathrm{~Pb}\left(\mathrm{Br}_{0.11} \mathrm{I}_{0.89}\right)_{3} \mathrm{NCs}$ by using a right-circularly polarized fs resonant pump $\left(\sigma^{+}\right)$and white light probe pulses $\left(\sigma^{+} / \sigma^{-}\right)$of duration two orders of magnitude shorter than the carrier lifetime (details in method section). $\sigma^{+}$pump pulse carries an angular momentum +1 , which excite carriers in $|+1 / 2\rangle$ spin state. Then the carriers undergo a spin-flip process and populate $|-1 / 2\rangle$ state, which can be monitored by $\sigma^{-}$probe. For example, $\sigma^{+}$pump bleach carriers in $|+1 / 2\rangle$ state due to state filling, and the probe $\sigma^{+}$and $\sigma^{-}$selectively detects the bleach of $|+1 / 2\rangle$ and $|-1 / 2\rangle$ state, respectively. The terminology used in this experiment is $\mathrm{C} 1$ when pump and probe pulses have the same helicity $\left(\sigma^{+} \sigma^{+}\right)$and $\mathrm{C} 2$ if they are opposite $\left(\sigma^{+} \sigma^{-}\right)$. From the bleach kinetics, we can estimate the spin relaxation time from the decay of $|+1 / 2\rangle$ bleach and the formation of $|-1 / 2\rangle$ bleach. The decay and formation kinetics merge, indicating that the carrier spin is in equilibrium. The schematics of the kinetics of spin depolarization is presented in Figure 4a and $\mathbf{4 b .}$ 


\section{WILEY-VCH}

As proof of concept, we studied the spin dynamics of $\mathrm{FAPbI}_{3}$ and $\mathrm{Cs}_{0.01} \mathrm{FA}_{0.99} \mathrm{~Pb}\left(\mathrm{Br}_{0.11} \mathrm{I}_{0.89}\right)_{3}$ NCs since their bandgaps are nearly the same. Figure $\mathbf{4 c}$ and $\mathbf{4 d}$ present the spin dynamics of the charge-carriers at the bleach maximum of $1.68 \mathrm{eV}\left(\mathrm{FAPbI}_{3}\right)$ and $1.72 \mathrm{eV}$ $\left(\mathrm{Cs}_{0.01} \mathrm{FA}_{0.99} \mathrm{~Pb}\left(\mathrm{Br}_{0.11} \mathrm{I}_{0.89}\right)_{3}\right)$ for $\sigma^{+}$pump (near bandedge $\left.1.77 \mathrm{eV}\right)$ and $\sigma^{+} / \sigma^{-}$probe as a function of the time delay when excited at a fluence of $5 \mu \mathrm{J} / \mathrm{cm}^{2}$. From the figures, it can be noticed that for $\mathrm{C} 1$, we observed an initial strong bleach followed by the decay. Decay of the bleach is due to the spin-flip of the carriers. Notably, for $\mathrm{C} 2$, we find a gradual rise of the bleach, which is proportional to the corresponding spin population. This simultaneous rise and decay of the $\mathrm{C} 1$ and $\mathrm{C} 2$ reaches equilibrium within 5 ps. To have an accurate spin lifetime, we have fitted the kinetics of $\mathrm{C} 1$ and $\mathrm{C} 2$ after 0.3 ps using a single exponential function, and the respective time constants are presented in Table 4. The polaron dominated system is known to possess fast spin-flip ${ }^{[61,62]}$, and among the two compositions discussed in the manuscript polarons are more dominated in $\mathrm{FAPbI}_{3}$ than in mixed NCs resulting in faster spin relaxation. Interestingly, by controlling polaron stabilty via composition tuning, spin-relaxation can be modulated in OILHP NCs, paving the way for their potential exploitation in the field of spintronics.

\section{Conclusions}

In summary, we have experimentally demonstrated the polaron mediated carrier protection in $\mathrm{FAPbI}_{3}$ and $\mathrm{Cs}_{0.01} \mathrm{FA}_{0.99} \mathrm{~Pb}\left(\mathrm{Br}_{0.11} \mathrm{I}_{0.89}\right)_{3} \mathrm{NCs}$ under controlled conditions. Our systematic studies reveal highly efficient carrier protection over nanosecond timescales due to polarons. The time required to form polarons in the $\mathrm{FAPbI}_{3}$ and $\mathrm{Cs}_{0.01} \mathrm{FA}_{0.99} \mathrm{~Pb}\left(\mathrm{Br}_{0.11} \mathrm{I}_{0.89}\right)_{3} \mathrm{NCs}$ are $\leq 0.75$ ps.

Noticeably, the $\mathrm{Cs}^{+}$cation and $\mathrm{Br}^{-}$halogen destabilize the polarons in $\mathrm{Cs}_{0.01} \mathrm{FA}_{0.99} \mathrm{~Pb}\left(\mathrm{Br}_{0.11} \mathrm{I}_{0.89}\right)_{3} \mathrm{NCs}$, and they decay slightly faster than the polarons in $\mathrm{FAPbI}_{3} \mathrm{NCs}$. Our results provide test beds for understanding and controlling the excellent polaron mediated carrier protection and spin-manipulation mechanism via composition tuning to develop nextgeneration opto-spintronics devices.

\section{Experimental Methods}




\section{WILEY-VCH}

Synthesis of $\mathrm{FAPbI}_{3} \mathrm{NCs}$ :

In a $25 \mathrm{~mL}$ three-necked flask, $61.1 \mathrm{mg} \mathrm{PbI} 2(0.133 \mathrm{mmol})$ was suspended in octadecene (4.6 $\mathrm{mL}$ ), heated to $60{ }^{\circ} \mathrm{C}$ and then dried under vacuum for $30 \mathrm{~min}$. Subsequently, the reaction mixture was heated to $110^{\circ} \mathrm{C}$ under nitrogen, followed by the syringe addition of dried solvents - oleylamine $(0.5 \mathrm{~mL})$ and oleic acid $(1.0 \mathrm{~mL})$. Once the $\mathrm{PbI}_{2}$ was dissolved, the reaction mixture was cooled to $80^{\circ} \mathrm{C}$. At this point, the mixture of formamidinium oleate stock solution $(5.0 \mathrm{~mL})$ (preparation details in Supporting Information) and ODE $(1.0 \mathrm{~mL})$ was injected into the reaction flask. After another $15 \mathrm{~s}$, the reaction mixture was cooled by a water-ice bath. ${ }^{[63]}$ The isolation and purification of $\mathrm{FAPbI}_{3} \mathrm{NCs}$ is detailed in Supporting Information.

Synthesis of $\mathrm{Cs}_{0.01} \mathrm{FA}_{0.99} \mathrm{~Pb}\left(\mathrm{Br}_{0.11} \mathrm{I}_{0.89}\right)_{3} \mathrm{NCs}$ :

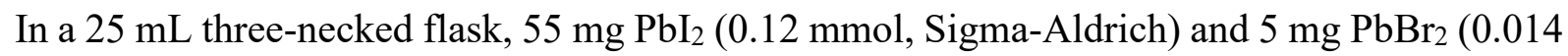
mmol, ABCR) were suspended in $4.6 \mathrm{~mL}$ octadecene. The reaction mixture was heated to 60 ${ }^{\circ} \mathrm{C}$ and dried under vacuum for $30 \mathrm{~min}$. Subsequently, the reaction mixture was heated to 110 ${ }^{\circ} \mathrm{C}$ in a nitrogen atmosphere, followed by the addition of $0.5 \mathrm{~mL}$ oleylamine (dried, Strem) and $1 \mathrm{~mL}$ oleic acid (dried). Once $\mathrm{PbI}_{2}$ and $\mathrm{PbBr}_{2}$ were dissolved, the reaction mixture was cooled to $80{ }^{\circ} \mathrm{C}$. At this point, a mixture of the formamidinium oleate $(4.8 \mathrm{~mL})$ and cesium oleate $(1.2$ $\mathrm{mL}$ ) solutions (preparation details in Supporting Information) was injected into the reaction flask. In $15 \mathrm{~s}$ the reaction mixture was cooled by a water-ice bath ${ }^{[12]}$. The isolation and purification of $\mathrm{Cs}_{0.01} \mathrm{FA}_{0.99} \mathrm{~Pb}\left(\mathrm{Br}_{0.11} \mathrm{I}_{0.89}\right)_{3} \mathrm{NCs}$ is detailed in Supporting Information.

\section{Ultrafast transient absorption spectroscopy:}

In ultrafast transient absorption (TA) spectroscopy, a difference in absorption of probe beam between excited and sample ground states are measured. A pump of $400 \mathrm{~nm}$ was generated by directing $800 \mathrm{~nm}, 120 \mathrm{fs}$, and $1 \mathrm{kHz}$ pulses from an amplifier to a second harmonic crystal. A dichroic beam splitter was used to separate generated second harmonic (pump) from the fundamental beam. The fundamental beam is focussed on a sapphire crystal, after passing 


\section{WILEY-VCH}

through a delay generating translation stage, to produce a white light continuum probe beam.

The resulting pump and weak probe beams are spatially overlapped onto the sample, and a change in absorbance of the probe is recorded using equation:

$$
\Delta A=-\left[\log \left(\frac{I_{e x}}{I_{0}}\right)\right]
$$

Where, $I_{e x}$ and $I_{0}$ represent the transmitted intensity of the probe beam in the presence and absence of the pump beam, respectively. Another portion of the femtosecond pulse focussed on the sapphire crystal that generates a white light continuum $(400-850 \mathrm{~nm})$. The time-delayed probe pulse measures the absorption change induced by the pump beam.

TA using circularly polarized light:

Circularly polarized pump and probe pulses are generated by using achromatic quarter waveplates.

\section{Supporting Information}

Supporting Information is available from the Wiley Online Library or from the author.

\section{Acknowledgements}

The authors gratefully acknowledge the Science and Engineering Research Board (Project no: CRG/2019/002808), DAE BRNS (Sanction no: 37(3)/14/26/2016-BRNS/37245), FIST Project for Department of Physics. K.V.A gratefully acknowledges the DST-IUSSTF BASE fellowship. M.C.B. acknowledges support as part of the Center for Hybrid Organic Inorganic Semiconductors for Energy (CHOISE) an Energy Frontier Research Center funded through the Office of Basic Energy Sciences, Office of Science within the US Department of Energy (DOE). M.V.K. acknowledgesfinancial support from the EuropeanUnion through Horizon 2020 research andinnovation programme (ERC Consolidator Grant SCALE-HALO, Grant Agreement No. 819740).

\section{References}

[1] D. A. Egger, A. M. Rappe, L. Kronik, Acc. Chem. Res. 2016, 49, 573.

[2] Y. Dong, Y. Zhao, S. Zhang, Y. Dai, L. Liu, Y. Li, Q. Chen, J. Mater. Chem. A 2018, 6, 21729.

[3] H. Zhu, M. T. Trinh, J. Wang, Y. Fu, P. P. Joshi, K. Miyata, S. Jin, X.-Y. Zhu, Adv. Mater. 2017, 29, 1603072. 


\section{WILEY-VCH}

[4] Q. Zhao, A. Hazarika, X. Chen, S. P. Harvey, B. W. Larson, G. R. Teeter, J. Liu, T. Song, C. Xiao, L. Shaw, M. Zhang, G. Li, M. C. Beard, J. M. Luther, Nat. Commun. 2019, 10, 10856.

[5] K. Liao, X. Hu, Y. Cheng, Z. Yu, Y. Xue, Y. Chen, Q. Gong, Adv. Opt. Mater. 2019, 7, 1900350.

[6] G. Li, K. Chen, Y. Cui, Y. Zhang, Y. Tian, B. Tian, Y. Hao, Y. Wu, H. Zhang, Adv. Opt. Mater. 2020, 8, 1902012.

[7] D. Shi, V. Adinolfi, R. Comin, M. Yuan, E. Alarousu, A. Buin, Y. Chen, S. Hoogland, A. Rothenberger, K. Katsiev, Y. Losovyj, X. Zhang, P. A. Dowben, O. F. Mohammed, E. H. Sargent, O. M. Bakr, Science 2015, 347, 519.

[8] J. Kang, L. W. Wang, J. Phys. Chem. Lett. 2017, 8, 489.

[9] K. Miyata, D. Meggiolaro, M. Tuan Trinh, P. P. Joshi, E. Mosconi, S. C. Jones, F. De Angelis, X. Y. Zhu, Sci. Adv. 2017, 3, e1701217.

[10] K. Miyata, T. L. Atallah, X. Y. Zhu, Sci. Adv. 2017, 3, e1701469.

[11] H. Kim, A. Hagfeldt, Adv. Opt. Mater. 2019, 7, 1801512.

[12] I. Lignos, V. Morad, Y. Shynkarenko, C. Bernasconi, R. M. Maceiczyk, L. Protesescu, F. Bertolotti, S. Kumar, S. T. Ochsenbein, N. Masciocchi, A. Guagliardi, C. J. Shih, M. I. Bodnarchuk, A. J. Demello, M. V. Kovalenko, ACS Nano 2018, 12, 5504.

[13] K. Wei, X. Zheng, X. Cheng, C. Shen, T. Jiang, Adv. Opt. Mater. 2016, 4, 1993.

[14] X. Zhang, D. Han, C. Wang, I. Muhammad, F. Zhang, A. Shmshad, X. Xue, W. Ji, S. Chang, H. Zhong, Adv. Opt. Mater. 2019, 7, 1900774.

[15] J. Aneesh, A. Swarnkar, V. Kumar Ravi, R. Sharma, A. Nag, K. V. Adarsh, J. Phys. Chem. C 2017, 121, 4734.

[16] L. M. Pazos-Outo, T. Patrick Xiao, E. Yablonovitch, J. Phys. Chem. Lett. 2018, 9, 1703.

[17] A. Mondal, J. Aneesh, V. Kumar Ravi, R. Sharma, W. J. Mir, M. C. Beard, A. Nag, K. V. Adarsh, Phys. Rev. B 2018, 98, 115418.

[18] S. Yakunin, L. Protesescu, F. Krieg, M. I. Bodnarchuk, G. Nedelcu, M. Humer, G. De Luca, M. Fiebig, W. Heiss, M. V. Kovalenko, Nat. Commun. 2015, 6, 8056.

[19] M. Saba, M. Cadelano, D. Marongiu, F. Chen, V. Sarritzu, N. Sestu, C. Figus, M. Aresti, R. Piras, A. Geddo Lehmann, C. Cannas, A. Musinu, F. Quochi, A. Mura, G. Bongiovanni, Nat. Commun. 2014, 5, 5049.

[20] J. Shi, Y. Li, J. Wu, H. Wu, Y. Luo, D. Li, J. J. Jasieniak, Q. Meng, Adv. Opt. Mater. 2020, 1902026.

[21] D. Zhao, E. E. M. Chia, Adv. Opt. Mater. 2020, 8, 1900783.

[22] J. Yang, X. Wen, H. Xia, R. Sheng, Q. Ma, J. Kim, P. Tapping, T. Harada, T. W. Kee, F. Huang, Y. B. Cheng, M. Green, A. Ho-Baillie, S. Huang, S. Shrestha, R. Patterson, G. Conibeer, Nat. Commun. 2017, 8, 14120.

[23] X. Jia, J. Jiang, Y. Zhang, J. Qiu, S. Wang, Z. Chen, N. Yuan, J. Ding, Appl. Phys. Lett. 2018, 112, 143903.

[24] D. A. Egger, A. Bera, D. Cahen, G. Hodes, T. Kirchartz, L. Kronik, R. Lovrincic, A. M. Rappe, D. R. Reichman, O. Yaffe, Adv. Mater. 2018, 30, 1800691.

[25] F. Zheng, L. W. Wang, Energy Environ. Sci. 2019, 12, 1219.

[26] P. P. Joshi, S. F. Maehrlein, X. Zhu, Adv. Mater. 2019, 31, 1803054.

[27] H. Zhu, K. Miyata, Y. Fu, J. Wang, P. P. Joshi, D. Niesner, K. W. Williams, S. Jin, X. Y. Zhu, Science 2016, 353, 1409.

[28] O. V. Kozlov, Y. N. Luponosov, A. N. Solodukhin, B. Flament, Y. Olivier, R. Lazzaroni, J. Cornil, S. A. Ponomarenko, M. S. Pshenichnikov, Adv. Opt. Mater. 2017, 5, 1700024.

[29] K. T. Munson, E. R. Kennehan, G. S. Doucette, J. B. Asbury, Chem 2018, 4, 2826.

[30] R. E. Beal, N. Zhou Hagströ, J. Barrier, M. D. McGehee, Matter 2020, 2, 207.

[31] R. J. Elliott, Phys. Rev. 1957, 108, 1384.

[32] Y. P. Rakovich, J. F. Donegan, Semicond. Nanocrystal Quantum Dots Synth. Assem. 


\section{WILEY-VCH}

Spectrosc. Appl. 2008, 257.

[33] M. I. Vasilevskiy, E. V Anda, S. S. Makler, Phys. Rev. B 2004, 70, 035318.

[34] S. Neutzner, F. Thouin, D. Cortecchia, A. Petrozza, C. Silva, A. R. Srimath Kandada, Phys. Rev. Mater. 2018, 2, 064605.

[35] Y. Yang, D. P. Ostrowski, R. M. France, K. Zhu, J. Van De Lagemaat, J. M. Luther, M. C. Beard, Nat. Photonics 2016, 10, 53.

[36] D. Christiansen, M. Selig, G. Berghäuser, R. Schmidt, I. Niehues, R. Schneider, A. Arora, S. Michaelis De Vasconcellos, R. Bratschitsch, E. Malic, A. Knorr, 2017, Phys. Rev. Lett. 2017, 119, 187402.

[37] M. Fu, P. Tamarat, J. B. Trebbia, M. I. Bodnarchuk, M. V. Kovalenko, J. Even, B. Lounis, Nat. Commun. 2018, 9, 3318.

[38] N. Mondal, A. De, S. Das, S. Paul, A. Samanta, Nanoscale 2019, 11, 9796.

[39] J. Chen, M. E. Messing, K. Zheng, T. Pullerits, J. Am. Chem. Soc. 2019, 141, 3532.

[40] R. Chakraborty, K. M. Sim, M. Shrivastava, K. V. Adarsh, D. S. Chung, A. Nag, ACS Appl. Energy Mater. 2019, 2, 3049.

[41] M. T. Trinh, X. Wu, D. Niesner, X. Y. Zhu, J. Mater. Chem. A 2015, 3, 9285.

[42] M. B. Price, J. Butkus, T. C. Jellicoe, A. Sadhanala, A. Briane, J. E. Halpert, K. Broch, J. M. Hodgkiss, R. H. Friend, F. Deschler, Nat. Commun. 2015, 6, 8420.

[43] J. Butkus, P. Vashishtha, K. Chen, J. K. Gallaher, S. K. K. Prasad, D. Z. Metin, G. Laufersky, N. Gaston, J. E. Halpert, J. M. Hodgkiss, Chem. Mater. 2017, 29, 3644.

[44] H. Telfah, A. Jamhawi, M. B. Teunis, R. Sardar, J. Liu, J. Phys. Chem. C 2017, 121, 28556.

[45] D. Rossi, H. Wang, Y. Dong, T. Qiao, X. Qian, D. H. Son, ACS Nano 2018, 12, 12436

[46] M. Li, J. Fu, Q. Xu, T. C. Sum, Adv. Mater. 2018, 31, 1802486.

[47] B. Ziaja, N. Medvedev, V. Tkachenko, T. Maltezopoulos, W. Wurth, Sci. Rep. 2015, 5, 18068.

[48] J. Dana, T. Debnath, H. N. Ghosh, J. Phys. Chem. Lett. 2016, 7, 3206.

[49] X. B. Zhang, T. Taliercio, S. Kolliakos, P. Lefebvre, J. Phys. Condens. Matter 2001, 13, 7053.

[50] A. L. Gurskii, S. V. Voitikov, Solid State Commun. 1999, 112, 339.

[51] M. Soltani, M. Certier, R. Evrard, E. Kartheuser, J. Appl. Phys. 1995, 78, 5626.

[52] P. Umari, E. Mosconi, F. De Angelis, J. Phys. Chem. Lett. 2018, 9, 620.

[53] A. A. Zhumekenov, M. I. Saidaminov, M. A. Haque, E. Alarousu, S. P. Sarmah, B. Murali, I. Dursun, X. H. Miao, A. L. Abdelhady, T. Wu, O. F. Mohammed, O. M. Bakr, ACS Energy Lett. 2016, 1, 32.

[54] A. C. Ferreira, A. Létoublon, S. Paofai, S. Raymond, C. Ecolivet, B. Rufflé, S. Cordier, C. Katan, M. I. Saidaminov, A. A. Zhumekenov, O. M. Bakr, J. Even, P. Bourges, Phys. Rev. Lett. 2018, 121, 085502.

[55] H. Zhu, T. Cai, M. Que, J. P. Song, B. M. Rubenstein, Z. Wang, O. Chen, J. Phys. Chem. Lett. 2018, 9, 4199.

[56] D. Giovanni, H. Ma, J. Chua, M. Grätzel, R. Ramesh, S. Mhaisalkar, N. Mathews, T. C. Sum, Nano Lett. 2015, 15, 1553.

[57] Y. Yang, M. Yang, K. Zhu, J. C. Johnson, J. J. Berry, J. Van De Lagemaat, M. C. Beard, Nat. Commun. 2016, 7, 12613.

[58] S. Fang, R. Zhu, T. Lai, Sci. Rep. 2017, 7, 287.

[59] D. Ghosh, A. R. Smith, A. B. Walker, M. S. Islam, Chem. Mater. 2018, 30, 5194.

[60] D. Ghosh, E. Welch, A. J. Neukirch, A. Zakhidov, S. Tretiak, J. Phys. Chem. Lett. 2020, 11, 3271 .

[61] S. Cha, Y. Hong, J. Yang, I. Maeng, S. J. Oh, K. Jeong, J. S. Suh, S. Haam, Y. M. Huh, H. Choi, J. Phys. Chem. C 2013, 117, 20371.

[62] A. J. Pearce, G. Burkard, 2D Mater. 2017, 4, 025114. 


\section{WILEY-VCH}

[63] L. Protesescu, S. Yakunin, S. Kumar, J. Bär, F. Bertolotti, N. Masciocchi, A. Guagliardi, M. Grotevent, I. Shorubalko, M. I. Bodnarchuk, C. J. Shih, M. V. Kovalenko, ACS Nano 2017, 11, 3119. 


\section{WILEY-VCH}
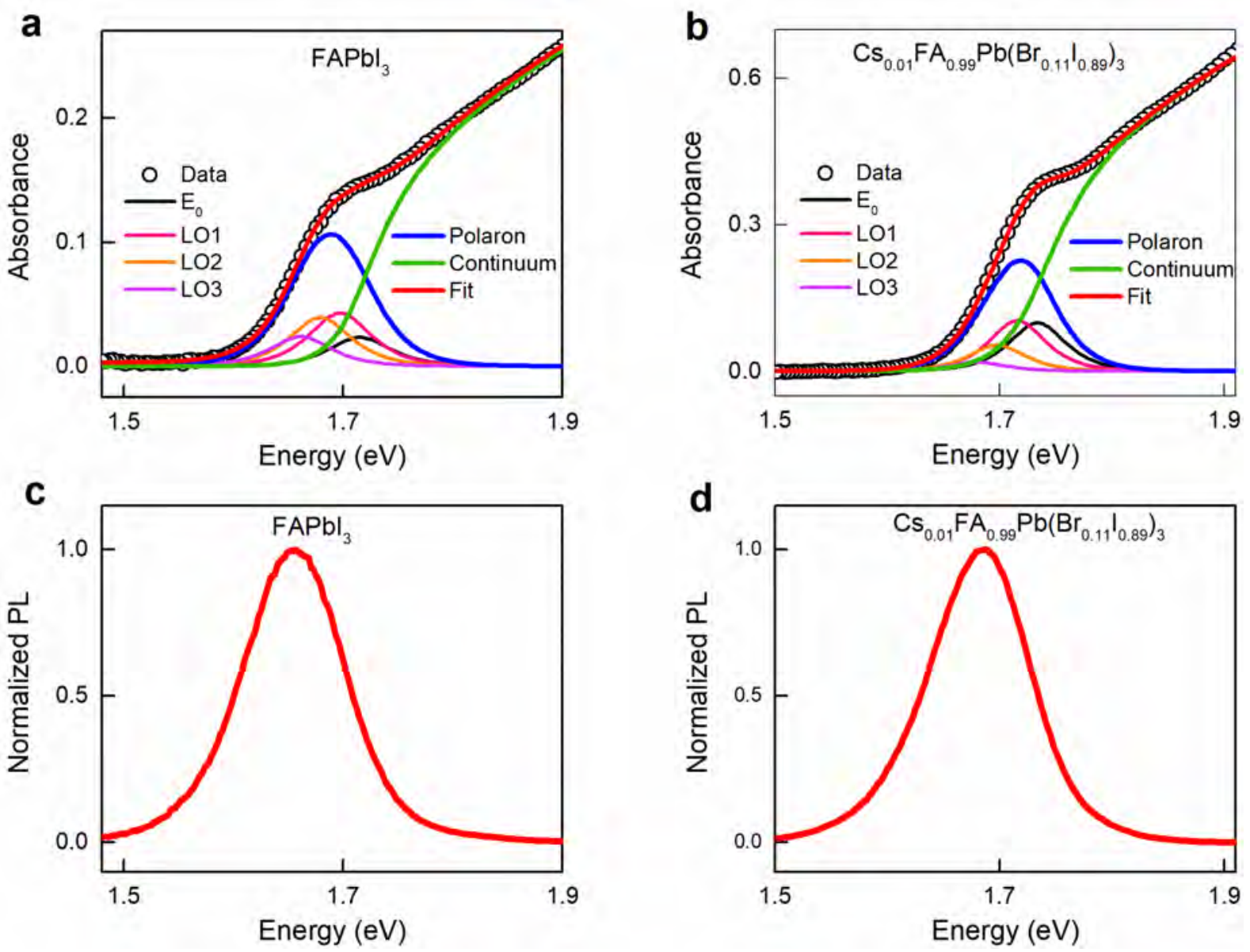

Figure 1. Optical characterization of NCs. Optical absorption spectrum with theoretical fit of a) $\mathrm{FAPbI}_{3} \mathrm{NCs}$ and b) $\mathrm{Cs}_{0.01} \mathrm{FA}_{0.99} \mathrm{~Pb}\left(\mathrm{Br}_{0.11} \mathrm{I}_{0.89}\right)_{3}$ NCs using modified Elliott's equation. Normalized PL of c) $\mathrm{FAPbI}_{3} \mathrm{NCs}$ and d) $\mathrm{Cs}_{0.01} \mathrm{FA}_{0.99} \mathrm{~Pb}\left(\mathrm{Br}_{0.11} \mathrm{I}_{0.89}\right)_{3} \mathrm{NCs}$. 


\section{WILEY-VCH}
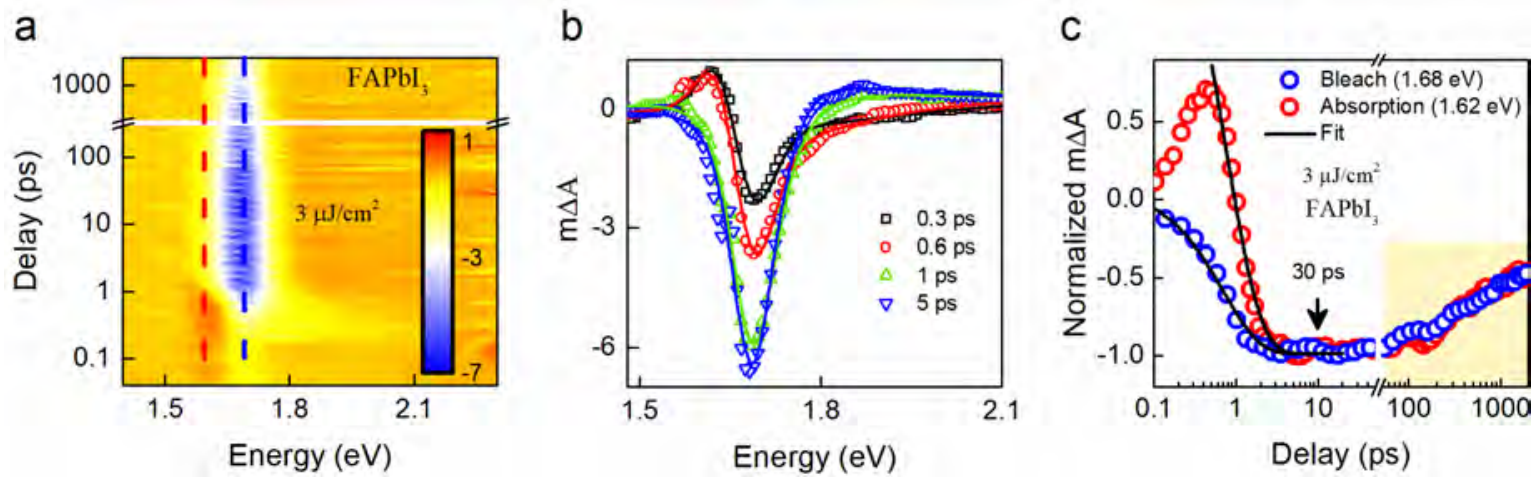

Figure 2. TA spectra of $\mathrm{FAPbI}_{3} \mathrm{NCs}$ for $400 \mathrm{~nm}$ excitation at a fluence of $3 \mu \mathrm{J} / \mathrm{cm}^{2}$. a) Contour plot of TA. b) Corresponding cross-sections at different pump-probe delay with hollow symbols representing experimental data and solid lines representing fit using Equation 2. c) Temporal evolution of redshifted absorption and polaronic bleach. 


\section{WILEY-VCH}
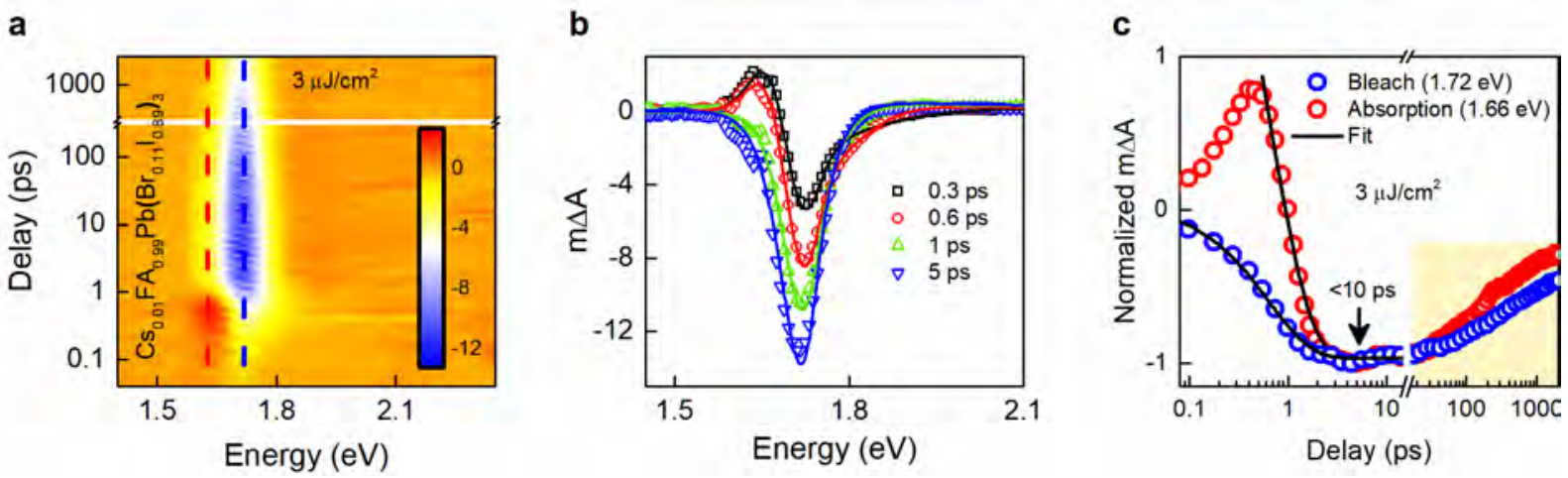

Figure 3.TA spectra of $\mathrm{Cs}_{0.01} \mathrm{FA}_{0.99} \mathrm{~Pb}\left(\mathrm{Br}_{0.11} \mathrm{I}_{0.89}\right)_{3} \mathrm{NCs}$ for $400 \mathrm{~nm}$ excitation at a fluence of $3 \mu \mathrm{J} / \mathrm{cm}^{2}$. a) Contour plot of TA. b) Corresponding cross-sections at different pump-probe delay with hollow symbols representing experimental data and solid lines representing fit using Equation 2. c) Temporal evolution of redshifted absorption and polaronic bleach. 


\section{WILEY-VCH}

a
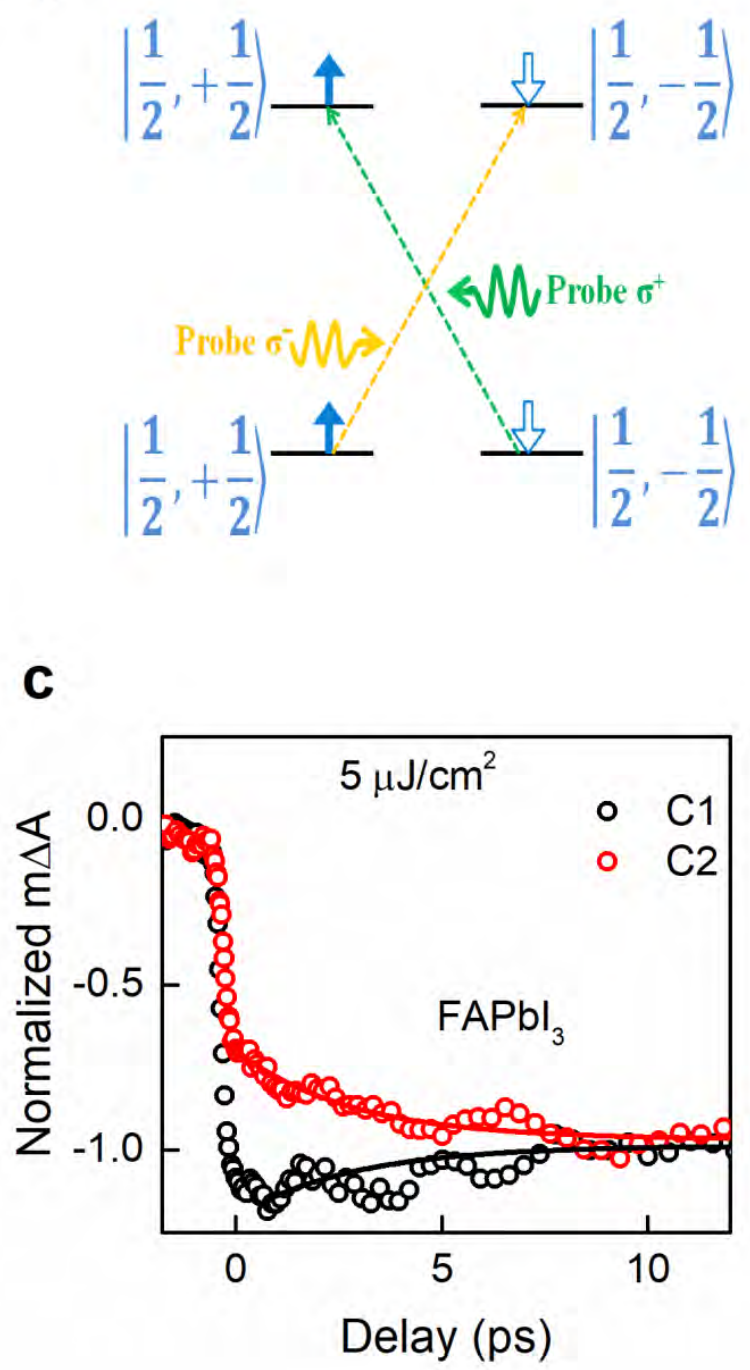

b

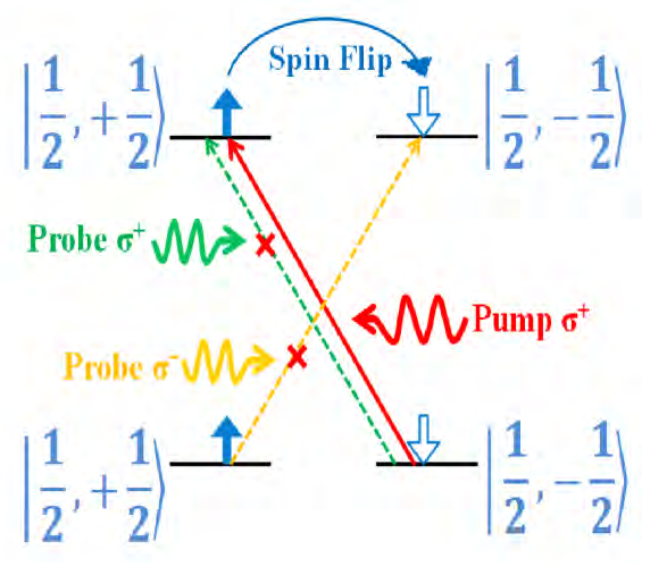

d

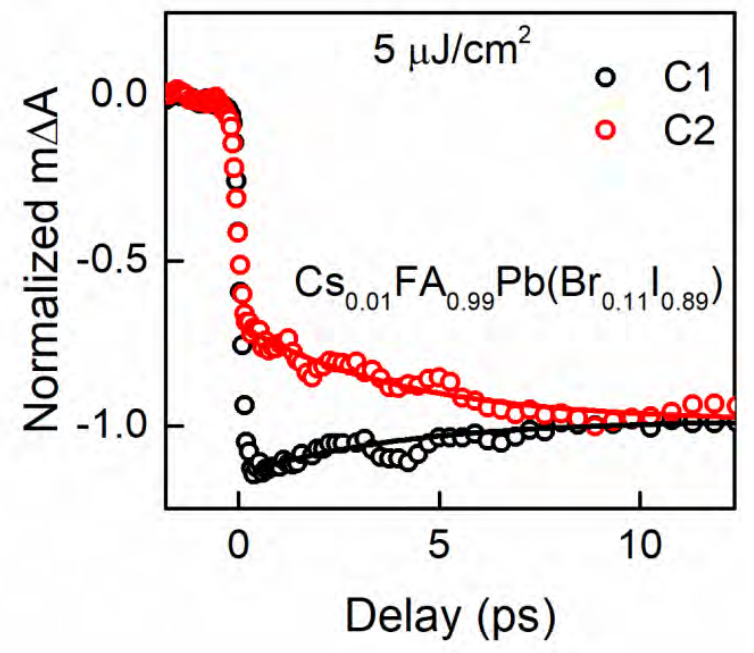

Figure 4. Spin dynamics in $\mathrm{Cs}_{0.01} \mathrm{FA}_{0.99} \mathrm{~Pb}\left(\mathrm{Br}_{0.11} \mathrm{I}_{0.89}\right)_{3} \mathrm{NCs}$ and $\mathrm{FAPbI}_{3} \mathrm{NCs}$. Schematic showing the optical selection rules in the a) absence and b) presence of pump. a) In the absence of pump, $\sigma^{+}$probe will make the transition of carriers from $m_{j}=|-1 / 2\rangle$ spin state of valence band to $m_{j}=|+1 / 2\rangle$ state of conduction band as per selection rules and conservation of momentum. Similarly, probing with $\sigma^{-}$will take $m_{j}=|+1 / 2\rangle$ state of valence band to $m_{j}=\mid-$ $1 / 2\rangle$ state of conduction band. b) Dynamics of the system excited with $\sigma^{+}$pump and probed with $\sigma^{+}$and $\sigma^{-}$probe. Initially due to band filling $\sigma^{+}$probe experience bleach, which will decay due to spin flip and corresponding growth of bleach for $\sigma^{-}$probe. Time evolution of $\mathrm{C} 1$ and $\mathrm{C} 2$ for a fluence $5 \mu \mathrm{J} / \mathrm{cm}^{2}$ of c) $\mathrm{FAPbI}_{3} \mathrm{NCs}$ and d) $\mathrm{Cs}_{0.01} \mathrm{FA}_{0.99} \mathrm{~Pb}\left(\mathrm{Br}_{0.11} \mathrm{I}_{0.89}\right)_{3} \mathrm{NCs}$. 


\section{WILEY-VCH}

Table 1. The fitting parameters $\left(\mathrm{Eg}, \mathrm{Eb}, \mathrm{S}, \Gamma_{\mathrm{ph}}\right.$, and $\left.\Gamma \mathrm{c}\right)$ obtained for $\mathrm{FAPbI}_{3}$ and $\mathrm{Cs}_{0.01} \mathrm{FA}_{0.99} \mathrm{~Pb}\left(\mathrm{Br}_{0.11} \mathrm{I}_{0.89}\right)_{3}$ NCs using modified Elliott equation:

\begin{tabular}{|c|c|c|c|c|c|}
\hline & $\begin{array}{l}\mathrm{Eg} \\
(\mathrm{eV})\end{array}$ & $\begin{array}{l}\text { Eb } \\
(\mathrm{meV})\end{array}$ & $\mathbf{S}$ & $\begin{array}{l}\Gamma_{\text {ph }} \\
(\mathrm{meV})\end{array}$ & $\begin{array}{l}\Gamma_{c} \\
(\mathrm{meV})\end{array}$ \\
\hline $\mathrm{FAPbI}_{3}$ & $1.716 \pm 0.003$ & $1.0 \pm 0.2$ & $1.8 \pm 0.2$ & $25 \pm 1$ & $20 \pm 2$ \\
\hline Cs0.01FA0.99Pb(Bro.11I0.89) & $1.735 \pm 0.003$ & $1.6 \pm 0.4$ & $1.0 \pm 0.1$ & $23 \pm 1$ & $24 \pm 2$ \\
\hline
\end{tabular}




\section{WILEY-VCH}

Table 2. The fitting parameters obtained for $\mathrm{FAPbI}_{3}$ at different probe delay using Equation 2 (expanded form in Equation $\mathrm{S} 1$ in Supporting Information) ( $\mathrm{E}_{\mathrm{LO}}=18 \mathrm{meV}$ and $\mathrm{E}_{\mathrm{g}}, \mathrm{E}_{\mathrm{b}}, \mathrm{S}, \Gamma_{\mathrm{ph}}$, and $\Gamma_{\mathrm{c}}$ were used as obtained from optical absorption fitting):

\begin{tabular}{lllll}
\hline & $\mathbf{\Delta E}$ & $\mathbf{E}_{\mathbf{f}}^{\mathbf{q}}$ & $\mathbf{T}_{\mathbf{c}}$ & $\mathbf{B}$ \\
& $(\mathbf{m e V})$ & $(\mathbf{e V})$ & $\mathbf{( K )}$ & \\
\hline $\mathbf{0 . 3} \mathbf{~ p s}$ & $51 \pm 4$ & $1.47 \pm 0.06$ & $1790 \pm 210$ & $0.50 \pm 0.02$ \\
$\mathbf{0 . 6} \mathbf{~ p s}$ & $55 \pm 3$ & $1.58 \pm 0.05$ & $1360 \pm 180$ & $0.40 \pm 0.02$ \\
$\mathbf{1} \mathbf{~ p s}$ & $9 \pm 1$ & $1.64 \pm 0.01$ & $490 \pm 35$ & $0.09 \pm 0.02$ \\
$\mathbf{5} \mathbf{~ p s}$ & $10 \pm 1$ & $1.62 \pm 0.05$ & $324 \pm 23$ & $0.001 \pm--$ \\
\hline
\end{tabular}




\section{WILEY-VCH}

Table 3. The fitting parameters obtained for $\mathrm{Cs}_{0.01} \mathrm{FA}_{0.99} \mathrm{~Pb}\left(\mathrm{Br}_{0.11} \mathrm{I}_{0.89}\right)_{3}$ at different probe delay using Equation 2 (expanded form in Equation S1 in Supporting Information) $\left(\mathrm{E}_{\mathrm{LO}}=18 \mathrm{meV}\right.$ and $E_{g}, E_{b}, S, \Gamma_{\mathrm{ph}}$, and $\Gamma_{\mathrm{c}}$ were used as obtained from optical absorption fitting):

\begin{tabular}{lllll}
\hline & $\Delta \mathbf{E}$ & $\mathbf{E}_{\mathbf{f}}^{\mathbf{q}}$ & $\mathbf{T}_{\mathbf{c}}$ & $\mathbf{B}$ \\
& $(\mathbf{m e V})$ & $(\mathbf{e V})$ & $(\mathbf{K})$ & \\
\hline $\mathbf{0 . 3} \mathbf{~ p s}$ & $53 \pm 1$ & $1.66 \pm 0.04$ & $1280 \pm 120$ & $0.61 \pm 0.01$ \\
$\mathbf{0 . 6} \mathbf{~ p s}$ & $54 \pm 2$ & $1.68 \pm 0.02$ & $1044 \pm 120$ & $0.36 \pm 0.01$ \\
$\mathbf{1} \mathbf{~ p s}$ & $11 \pm 2$ & $1.69 \pm 0.01$ & $420 \pm 23$ & $0.001 \pm--$ \\
$\mathbf{5} \mathbf{~ p s}$ & $9 \pm 1$ & $1.65 \pm 0.02$ & $410 \pm 12$ & $0.001 \pm--$ \\
\hline
\end{tabular}




\section{WILEY-VCH}

Table 4. Spin relaxation time constant calculated by fitting the experimental data using single exponential function at fluence of $5 \mu \mathrm{J} / \mathrm{cm}^{2}$.

\begin{tabular}{lll}
\hline & FAPbI $_{3}$ & Cs0.01FA0.99Pb(Bro.11I0.89)3 \\
\hline C1 & $2.8 \pm 0.7 \mathrm{ps}$ & $4.0 \pm 0.7 \mathrm{ps}$ \\
$\mathrm{C2}$ & $2.8 \pm 0.3 \mathrm{ps}$ & $4.0 \pm 0.4 \mathrm{ps}$ \\
\hline
\end{tabular}




\section{WILEY-VCH}

\section{The table of contents entry}

The polaron and spin dynamics in organic-inorganic lead halide perovskite nanocrystals is examined using ultrafast transient absorption spectroscopy.

\section{Keyword}

Polarons, organic-inorganic lead halide perovskite, spin dynamics

\section{Authors}

Megha Shrivastava, Maryna I. Bodnarchuk, Abhijit Hazarika, Joseph M. Luther, Matthew C. Beard, Maksym V. Kovalenko, and K. V. Adarsh*

\section{Title}

Polaron and Spin Dynamics in Organic-Inorganic lead Halide Perovskite Nanocrystals.

\section{TOC Figure}

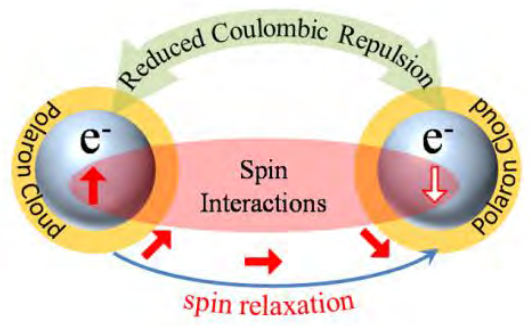

